\title{
Vulnerability, Capabilities and New Models of Human Development in a Global Socio-Economic Perspective
}

\author{
Danilo Boffa \\ Università degli Studi di Teramo \\ Italy
}

\begin{abstract}
The paper aims to shown how the changing idea of vulnerability, considered as a part of human being could be the base for a social, economic and political theory drawn up starting by the Capability Approach. The drafting of this theory, completed by a precise list of capabilities, as a guide to develop new policies, give the foundation to new models of Human Development: at an international level, the Human Development Index - and the other originated from it - shows more accurately the situation of Human Development, taking into account not only specific aspects of human living, but also considering physical, economic, social and political inequalities, according to the Sustainable Development Goals of the 2030 Agenda. The paper wants to demonstrate that speaking about capabilities is more productive than speaking about rights to overcome inequalities.
\end{abstract}

Keywords: vulnerability, capability, inequality, development, right, human-being, well-being.

\section{Introduction}

The project of this paper is to show how the equal condition of economic, social and political vulnerability of people can be the glue that permits to overcome inequalities, aiming to consider humans as a combination of capabilities and functioning's, whose support and development constitute the basis for a public and shared ethics, socially and economically speaking. The Capability Approach, drawn up by Amartya Sen and Martha Nussbaum, could be intertwined with the idea of a common vulnerability, which describes human condition, although with diverse expressions in terms of kind and degree, but due to this it makes everyone equal in a condition of inequality. The paper also aims to discuss the correlation between human rights and capabilities, trying to discuss if there are any reason to prefer one or the other in treating human development. The recent discussions about human development has drawn up new models to measure human well-being: Human Development Index and its derivates (also the specific case represented by BES in Italy) aim to overcome the traditional theory based on the Gross National Product per capita used for measuring human well-being, trying to integrate these measurements with the idea of capability, whose support and promotion could be the base for new economic, political and social measures.

\section{Vulnerability and inequality}

The work done by Martha Nussbaum is aimed at the analysis of the inequalities and at the erosion of the same ones, to achieve the social equality that represents the ultimate attainment of the discourse on political philosophy. And that is how the author devotes paragraphs, chapters, essays, whole books on inequality, not merely developing a general and abstract discourse, but analyzing all kinds of social discrimination, highlighting the similarities, but also the special features of them. This commitment, more specifically, results in a concrete transposition of the political theory, in order to answer to three fundamental themes: 1. Disability; 2. Multiculturalism; 3. Gender inequality (Pizzo, 2014). The permeability of the idea of vulnerability is the glue that connects these "categories" of inequality: the aim of that speech is, with the risk of trivializing, to demonstrate how the differences between diverse social groups are nothing more than different declinations of the condition of perpetual vulnerability, which is an essential characteristic of human beings as such. Through this cognitive effort, Nussbaum wants to lead us to a reform of the welfare system, clearly outdated and no longer able to meet the needs of the most vulnerable individuals. Referring to the theme of disability she starts to reason on inequality. Beginning with the understanding of what this kind of discrimination represent for society and what it represents, in fact, for those who live in this state of extreme need, of extreme vulnerability, the topic of disability becomes a paradigm shift to show how the capability approach offers some avenues of resolution. 
The definition, given by Nussbaum, of disabled people matches the description of one person, whose performance of its personal functions is negatively affected by the presence of objective obstacles of various kinds. This failure to comply with the standard operation of the person causes a social division, that places disabled individuals in a social range different from that of able-bodied people. Everyone can easily see that the difference between the two groups is represented "only" by the fact that, while the latter ones can rely on its own strength to face their everyday life, the first ones need further assistance to carry out their functions and to achieve their life expectancy (Pizzo, 2014).

In a so presented situation does not seem to be nothing disconcerting, and indeed discrimination seems to present a simple objective description of a substantial difference. Discrimination arises because there is an intrinsic difference in the balance of power between people with disabilities and able-bodied individuals and, when we recognise the diversity, due to that diversity we try to produce different rights for vulnerable. This eliminates the above, with respect to disability as a variation of the common human condition of vulnerability, and is, according to the nussbaumian reconstruction, just the fear of acknowledging in a disabled person our same vulnerability that leads us to experience a feeling of disgust, that reminds us of our mortality and our insecurity towards life (Nussbaum, 2004).

Such reconstruction has strong social implications, since similar considerations feed some general laxity around the issue of disability: although you deem appropriate policy measures to support these vulnerable groups, these in a specific period of crisis, which is the one we are experiencing - turn out to be mere unnecessary expenses, as well as the disabled were at the time of the issuance of the social contract (Rawls, 1971), and as long as they remain excluded in the moment of enjoyment for the contract results (Nussbaum, 2006). Nussbaum also analyzes the dependency status of persons with disabilities from the point of view of those who "care" and not only lends to those who received that care, and here the author's criticisms do not wait: odds are, the condition of need of the disabled person is permanent and this turns out to be time consuming and costly. A situation that is not fully protected by the Government, but it adds further vulnerability's factors.

The paradigm of mutual benefit and reciprocity, which has characterized all the traditional theories of the social contract (Nussbaum, 2006), must be overcome in favour of a concept that does not consider the initial condition of liberty, equality and independence, which is inevitably denied to every person with a disability, but rather look at the goal: ensuring that every individual, who is member of the society, lived his life as a free, equal and independent person.

The element of disgust - in combination with that of shame - mentioned above is present, according to Nussbaum, in other discriminatory cases, particularly with reference to discrimination based on race and sexual orientation. The author is fighting vehemently against what she calls the politics of disgust that contrasts with the politics of humanity (Nussbaum, 2004; 2010), a policy that is based on the equal respect for every individual, which is made very difficult by the fact that, on the one hand, individuals belonging to different cultures, on the other hand, LGBT individuals have been "demonized" by public opinion, presented as something to be feared, from which be disgusted because sources of contamination and impurities (Nussbaum, 2004; 2010). The case of sexual orientation seems to be similar to that of racism, because in every of these cases people are classified by a characteristic feature and then are denied to them fundamental opportunities in many areas due to that feature (Nussbaum, 2010).

For example, African-Americans were portrayed as mere animals, as part of a species other than humans, while such as homosexuals are linked to the concept of hyper-sexuality; the difference exists since, contrary to what is true for disability and racism, LGBT individuals can disguise the characteristic associated with discrimination, potentially for their entire life, while others do not, and this, according to the author, reveals a cautious optimism to overcome homophobia (Protasi, 2012). On the other hand, it is equally true that the overcoming of discrimination regarding sexual identity carries with it very noble and acceptable reasons, since it concerns the most intimate sphere of life and the right of every individual to choose their own project of life and the person to undertake it with. Instead, the concept of race is invented, not relevant scientifically, but it has gained relevance historically (Protasi, 2012). Nussbaum found the major concerns in discrimination against women. The author believes that feminism is the discriminatory factor that best characterized the history of mankind, which shaped the society as it is structured today and that will be the most difficult discriminatory phenomenon to eliminate. 
This is because, as explained by Thomas (1980), the concept of man's masculinity is related in a compelling way to the rule over women, and this is peculiar, because there is no concept of "true white man" or "real heterosexual person" connected to others discrimination, which have similar meaning or approach to the concept of "real man" (Protasi, 2012). Nussbaum seeks to show how, for the transition from a sexist to a non-sexist society, we need a change of people at a much deeper level than required for a homophobe to become non-homophobe: in the latter case it would be enough assume an attitude of "live and let live" - as many of them do today - and, although a deeper understanding of gender identity would undoubtedly be positive, it is not strictly necessary for the quiet life in society. In the first case the social structure, family, sexual attitudes in sexist individual is so ingrained that the passing looks even today a mirage, also because of the sense of "private/privacy", which is going to be treated in the next paragraph, which distorts the meaning of rights, trying to justify the circumvention of respecting them in the private sphere (Protasi, 2012). The capability approach that I'm going to present in the next section provides important insights to address the issues above, through a different perspective from that traditionally based on the appeal to the right for the erosion of the social and economic inequalities.

\section{The Capability Approach: from Amartya Sen to Martha Nussbaum}

The first organic formulation of the Capability Approach is provided by Amartya Sen, Indian Economist, Nobel Prize winner in 1998, that develops it gradually, beginning in the early 1970s, as a continuation of a reflection focused on more strictly economic and social choice theory issues - in controversy with the traditional welfare economics and with the theory of choice to which it is modelled -, giving it an explicit formulation in the Tanner Lecture named "Equality of What?" (Sen, 1979), in which it appears the expression "Capability Approach", commonly used to define it. Despite some disagreement among scholars about the best description of the Capability Approach, it is generally understood as a "conceptual schema for normative exercises" (Robeyns, 2011), which can be summarized in the following: 1. The analysis of individual well-being; 2 . The assessment and analysis of social organization; 3. The development of policies and proposals for a drastic change in society.

Deeply convinced that the economic analysis could contribute to the ethics and that some of the most lacerating ethical and social problems are of an economic nature, Sen defends a conception of public morality which recognises to the individual freedom a central role in any assessment of the social system as an essential element of social arrangements. The author also believes that this perspective has some advantages over other approaches and may also have far-reaching implications for the evaluation of social institutions and political choices. It is a social, or public, ethics, because it is devoid of a strong individual characteristic. The primary interest is not so much to provide criteria for assessing the "rightness" of individual actions or to guide the individual in their personal conduct, but rather to provide criteria for making decisions in the public interest, to formulate judgments on social structures and on public policies (Sen,1993). An attempt to offer a solution to deal with issues such as inequality, poverty, famine, or to do evaluations of different political and social models. The line between public ethics and political philosophy is so weak: the interest in these issues is both ethical and political. Martha Nussbaum (2001) outlined the capacity approach - in general, not in her specific version - as formed by two main clusters: one focused on the comparison of the quality of life and the other on the formulation of a theory of justice. The two main themes share attention to what individuals are and do, as well as on five basic principles: 1 . Treat people as ends (and not as means); 2. The attention given to freedom and choice rather than results; 3. Pluralism of values; 4. Deep concern about the more entrenched social injustice; 5 . Give an urgent mission to Governments (Robeyns, 2011).

The approach, in Nussbaum's version, is presented as a non-consequentiality view: the realization of a set of key skills is a normative principle able to determine the value of the action, regardless of the consequences of it. So, while Sen recognizes to the Capability Approach a function more appropriate than theories mainly used for the evaluation of the quality of life, Nussbaum intends to overcome this merely comparative use, trying to draw up an examination of how capabilities, together with the idea of a threshold level of these, can provide a basis for the elaboration of fundamental constitutional principles, that citizens are entitled to demand from their Governments (Nussbaum, 2000). Despite the new theory appears as an ethic with a social character, individual aspects are not denied: the interest of Sen is aimed capabilities and functionings of each person, rather than to those of society at large or of a particular community; the capabilities are therefore, deals with the theory, individual skills. Among the issues, which the Capability Approach tries to find answers to, there are problems related to the allocation of assets and expenses. From this point of view, it takes the form of a theory of justice, if associated conceptually in those theories regulations that formulate principles of distributive justice. 
Principles which guide the distribution of resources in society to define the political, economic and social conditions that guarantee the equal treatment of community members. Although the American philosopher follows the Indian colleague in arguing that this approach is an assessment of justice based on the capability (Sen, 1985), Nussbaum integrates this concept through the formulation of an objectivistic meta-ethic theory, claiming that there are some natural features of human life that should be considered inherently good, by means of which you can find a list of key skills and a "minimum threshold" of such basic skills, in that attribute legal-political value as the foundation of constitutionally recognized principles.

\section{Basic Capabilities, Internal Capabilities and Combined Capabilities against Human Rights}

The most important contribution that Nussbaum brings to the theory about capabilities is the precise formulation of a list of basic and fundamental capabilities, each of which, at least respecting a minimum threshold of such capabilities, should be "supplied" to every individual to allow him to really live in a humane manner. Is the main difference from the original formulation of the theory made by Sen, who does not consider at all the possibility to include in his version or, in fact, a list of key skills, which in his view had to be the result of a democratic process, nor the concept of threshold, introduced solely by Nussbaum. This list is the result of years of cross-cultural discussions, comparing old versions and other newer and still open to change by the will of the author herself, suggesting that it a kind of overlapping consensus (this expression was used, for the first time, by Rawls (1993) to define the notion that different individuals would accept this concept as moral core of a political conception, without sharing any particular metaphysical interpretation of the world, no ethical-religious vision, or even no particular person or conception of human nature) by people with very different conceptions of human life (Nussbaum, 2000, 2001; Rawls, 1993).

This is the list as the author presented it: 1) Life; 2) Bodily Health; 3) Bodily Integrity; 4) Senses, Imagination, and Thought; 5) Emotions; 6) Practical Reason 7) Affiliation (a. Being able to live with and toward others; $b$. Having the social bases of self-respect and non-humiliation; ; 8) Other Species; 9) Play; 10) Control over one's environment (a. Political; b. Material). Capabilities are defined by using the notion of functionings available in the subject, which are "beings and doings", intended as the realization of a potential status, made of capabilities. They are status or activities that a person can undertake: to be well fed or to be undernourished, be educated or illiterate, being part of a social organization rather than a criminal gang are examples of "beings" (good or not), while traveling, taking care of children and animals, vote in elections, taking drugs or killing animals are examples of "doings" (good or not). The correlation between the categories mentioned, then, is summarised as follows: Human goodness $\rightarrow$ Capability (of functioning) $\rightarrow$ Functioning $\rightarrow$ Utility (Clark, 2008).

What the author describes is an approach that could be called holistic, all-encompassing, and not piecemeal, sectional interest. Ingrid Robeyns (2011) explains very clearly how what is relevant to the author are not the opportunities that are open before each one each for herself, but the combinations or sets of functioning that are available: Suppose I am a low-skilled poor single parent who lives in a society without decent social provisions. Take the following functionings: 1 . To hold a job, which will require me to spend many hours on working and commuting but will generate the income needed to properly feed myself and my family; 2 . To care for my children at home and give them all the attention, care and supervision they need. In a piecemeal analysis, both 1. And 2. Are opportunities open to me, but they are not both together open to me (Robeyns, 2011).

Nussbaum argues that the discourse about the capabilities is more prolific than it used to be that the human rights, with particular reference to what we usually define as "fundamental human rights". The author does not minimally intend to defend the hypothesis of an antithesis between her theory and those focused on the concept of law, but the aim is to highlight how not only the ability to have a close relationship with human rights, being a notion that we could say "encompasses" the right's one, but also that speaking about capability, rather than human rights, helps to avoid three pitfalls:

1. The suggestion that the rights are assured when the State does nothing - when, instead, the approach based on capabilities points out that all of them require action by governments for their protection and enforcement -;

2. The distinction between first-generation rights (civil and political) and second-generation rights (social and economic) because the capability-based approach makes it clear that each capability has a socio-economic aspect, which requires a taxing and a spending for its application;

3. The consideration that human rights do not have the same strength depending on whether it refers to something in the public domain or vice versa in the private sphere. 
The notion of "private", according to Nussbaum, causes confusion, because it puts together considerations that should be kept separate: isolation, secrecy concerning information, autonomy, intimacy. To support, for example, that sexual facts it's nobody's business, we are referring mainly to the fact that they are intimate areas of life that an individual has the right to keep hidden; We can also allude to the autonomy interest that individuals have in these activities. None of these uses of "private" implies that there is a special place privileged - the house - that the law cannot adjust for the sole reason that it is not a public place (Protasi, 2012).

Moreover, we are in a situation far from agreement on what is the nature of rights, whether they are pre-political rights or legal-institutional artifacts; the fact that they are prerogatives of individuals individually intend or considered in groups; There is also disagreement on the right/duty relationship: if you have the right to something automatically arises the duty for someone to "give it" to you? How do you establish who this "someone" will be (Nussbaum, 2000)?

As also supported by Williams (1987), the appeal to theories based on rights is problematic and needs some clarifications, while capabilities have very clear interest and what is the goal to be achieved. The best way of combining the two concepts is approaching the idea of law to that, already introduced in this paper, combined capacity; also because the image purely "westernised" of law is still very linked to 'writing form', which is necessary for the enforcement, and despite the advent of modern constitutionalism and constitutional models approach, we can easily identify examples through which it is easy to show how even formally guaranteed by constitutional laws, and not, in substance some rights are not. Let us think, for example, in those countries where citizens have formally the right of political participation, because it formalized on paper, but de facto does not have that capability, due to violence they could suffer, or because this right is denied to women for an almost medieval heritage, or due to, for example, arbitrary cancellation of electives (UNDP, 2000).

\section{Human Development as new political paradigm: The United Nation Development Programme}

The work made by Sen and Nussbaum has found operational translations at an international level, giving a theoretical base for a radical change in the way we conceive Human Development, well-being, and consequently, the policy of vulnerabilities' and disabilities' management, along with climate and environmental preservation as part of development and as a responsible behaviour for coming generations. It's here that born and grow institutions and associations, with the hard task to disclose and, at the same time, to guide the policies. The United Nations Development Programme is a subsidiary body of the United Nations, born on $1{ }^{\text {st }}$ January 1966, after the resolution of the General Assembly held on $22^{\text {nd }}$ November of the previous year. It is an international organization whose operating zone includes 177 States and whose primary mission consists in poverty eradication, inequality erosion, trying to give support to these States in developing active policies which promote human development in all its aspects. UNDP is working, therefore, to protect our planet, to reduce climate-changing and, at the same time, helping - also economically - people that were affected by environmental disasters. The tasks of reaching peace and prosperity, in addition to those who were mentioned before, are summarized in an official document, undersigned by Nations who joined the Program: Sustainable Development Goals for 2030 (UN, 2015). Further to this, the Program aims to be the implement in protecting human rights and work for the empowerment of women, of minorities and of the most vulnerable population groups.

The most important tool, commissioned by UNDP and used to communicate the steps forward done by the Program, is the annual "Human Development Report", through which the key problems about development is debated, and together with it, it proposes supportive measures, innovative analysis, and often controversial political proposals. It is an independent publication and its editorial autonomy is guaranteed by a special resolution of the General Assembly, who recognised the Report as an independent intellectual exercise and as an important tool for the awareness on human development all around the world. More than 140 independent national reports were translated in more than a dozen of languages and were published and in over 100 nations (Alessandrini, 2013).

Trough the Human Development Report, the United Nations, according to the mission of the Human Development Program, every year, let everyone knows the challenges that it intends to face up to and the tasks that were beingreached by the Program itself, serving as guidance for the policymakers both for national and international policies. The first report was published in 1990, and its diffusion has marked a great breakthrough, particularly in the way that the poverty is intended, not only in quantitative terms, but also and specifically, in qualitative terms. 
In the document's drawing up was truly relevant the influences from the Capabilities Approach that I've described before, at the point that the Chapter II is completely dedicated at this argument and Sen was sitting at that working table as a consultant. With this report, the United Nations translates the clarion interest in new concepts of human development and human well-being, in a brand-new index for the social and economic measurements of the human welfare, that could be a solid support to the Gross National Product (GNP), the classical index used for that kind of measurements: the Human Development Index (HDI) (UNDP, 1990).

\section{Beyond the Gross National Product}

In 2008, the French President Nicholas Sarkozy, conscious of the inadequacy of the statistical data for welfare measurements both socially and economically speaking, brought together, in a special commission called "Commission on the Measurement of Economic Performance and Social Progress", Nobel prized Joseph E. Stiglitz as Commission's President, Nobel prized Amartya Sen as consultant and Prof. Jean-Paul Fitoussi as coordinator. The main task for the Commission was to find the limits in using common statistic indexes, some of which was considered not more usable to give a good point of view of the reality they intended to have. Particularly, the Commission focused on the Gross National Product (GNP) - also called Gross Domestic Product -, commonly used in welfare measurements in the economically advanced States, as well as the index which comes from it: GNP per capita (European Commssion, 2009).

The outcome of the work of the Commission is included in the "Report of the Sarkozy's Commission on the Measurement of Economic Performance and Social Progress" - better known as Stiglitz Report or Stiglitz-SenFitoussi Report - delivered in September 2009, then published and used as a model by different and multilevel realities (Sen; Stiglitz; Fitoussi, 2009). The fact that we commonly link the richness generated by a State with its well-being brings to light not a few questions, and - write Nussbaum - even if we decide to measure the quality of human life in strictly monetary terms and to use a single average rather than looking to the distribution, the GNP per capita wouldn't be the most interesting element to consider (Nussbaum, 2011). In the Report can be read the reason that leads to a radical change in studies and in statistical surveys, as well as it is made clear that those considerations are addressed to diverse categories of social actors, including those who are the most important for this dissertation: Governments and politicians, to whom it was given 12 recommendations:

1. In assessing the material wellbeing, you look to income and consumption rather than production, because living standards are more closely associated with measures of real income of households and consumption; It is also possible to expand production while decreasing income and vice versa;

2. Emphasize the family perspective, since some data they view as family incomes have declined compared to income per capita;

3. Consider the income and consumption in conjunction with the heritage, we must consider the possibility that a family has of investing in assets of consumer goods and not in durable goods, increasing their immediate well-being, to the detriment of the future;

4. Pay more attention to the distribution of income, consumption and wealth, since it could happen - and it happens in most countries with low economic development - that the increase in the median income takes place unevenly, "leaving out", therefore, an important part of the population, of which we do can't know the "fate" through the GDP;

5. Expand the measures for the income of non-market activities, and hence to unpaid work, to those services that households produce for their own consumption, which are not considered in official measurements (Nussbaum, 2000);

6. People's quality of life depends on the objective conditions and capabilities, should, therefore, consider different aspects of human life for welfare assessment. From the Report emerge these fundamental dimensions: I. Material standards of living (income, consumption and wealth); II. Health; III. Education; IV. Personal Activities including work; V. Political view and Government; VI. Integration and social relations; VII. Environment (present and future conditions); VIII. Economic insecurity, as well as of physical insecurity (there it must be considered the list of capabilities made by Nussbaum (2000), which clearly has inspired the one in this Report);

7. The quality-of-life indicators, in all their dimensions, should evaluate inequalities comprehensively, namely, taking into account: people, socioeconomic groups, gender inequality and that one between generations, as well as the inequalities, which have recently appeared, such as those related to immigration; 
8. Inquiries should be designed to assess the links between the various aspects of quality of life for every person, and this information should be used in the design of policies in various fields, developing policies which, although targeted at specific areas, considering the impact of the same quality of life indicators jointly, to address aspects and needs of disadvantaged people in different fields;

9. Statistical offices should provide useful information to aggregate data about various aspects of the quality of life, to allow the construction of different indexes, although there are requests for a formulation of a single synthetic index, because, if it is true that the quality-of-life measurement requires a variety of indicators, we need to develop a synthetic indicator that considers all these variables;

10. Objective and subjective measures of well-being to provide key information on the quality of people's lives. Statistical offices should include questions to capture the evaluations of people's lives, hedonistic experiences and their evaluations of priority, to regard not only to the objective welfare which are mentioned in the previous recommendations, but also to the subjective well-being, which consists in the perception of their own lives, their happiness or satisfaction, their positive emotions such as joy and pride, and negative emotions such as pain and concerns;

11. Sustainability assessment requires an instrument panel of clearly identified indicators. The distinguishing feature of the components of this dashboard should be to be interpretable as changes in underlying some "stock". A monetary sustainability index has its place in the dash, but the current state of the art, should remain essentially focused on the economics of sustainability, because sustainability assessment of well-being must be made separately, identifying the variations of "stock" of human, natural, social and also economic resources needed for human well-being;

12. The environmental aspects of sustainability deserve a separate follow-up, on the basis of a well-chosen set of physical indicators. In particular there is a need for a clear indicator of our proximity to dangerous levels of environmental damage (such as those associated with climate change or the depletion of fishing stocks), which, as well as for the assessment of sustainability, cannot bind to a monetary value, with particular regard to irreversible environmental changes, or, for example, to the evaluation of changes in greenhouse gas concentrations in the atmosphere, to associate it with precise thresholds for a climate change risk (Sen; Stiglitz; Fitoussi, 2009).

A change in this sense is not only desirable, but necessary, because being able to "photograph" in the as accurately as possible way, is the first step to build national and international policies that are effective in achieving the expected result, on schedule. As noted by then still candidate for President of the United States, Robert Kennedy, in a speech on 18 March 1968 at the University of Kansas: «Even if we act to erase material poverty, there is another greater task, it is to confront the poverty of satisfaction - purpose and dignity - that afflicts us all. Too much and for too long, we seemed to have surrendered personal excellence and community values in the mere accumulation of material things. Our Gross National Product, now, is over $\$ 800$ billion dollars a year, but that Gross National Product - if we judge the United States of America by that - that Gross National Product counts air pollution and cigarette advertising, and ambulances to clear our highways of carnage. It counts special locks for our doors and the jails for the people who break them. It counts the destruction of the redwood and the loss of our natural wonder in chaotic sprawl. It counts napalm and counts nuclear warheads and armored cars for the police to fight the riots in our cities. It counts Whitman's rifle and Speck's knife, and the television programs which glorify violence in order to sell toys to our children. Yet the gross national product does not allow for the health of our children, the quality of their education or the joy of their play. It does not include the beauty of our poetry or the strength of our marriages, the intelligence of our public debate or the integrity of our public officials. It measures neither our wit nor our courage, neither our wisdom nor our learning, neither our compassion nor our devotion to our country, it measures everything in short, except that which makes life worthwhile. And it can tell us everything about America except why we are proud that we are Americans. If this is true here at home, so it is true elsewhere in world» (Kennedy, 1968).

In the same years, the King of Bhutan, Jigme Singye Wangchuck, introduced an index called "Gross National Happiness (GNH)", which is based on 4 pillars: 1) Equitable and sustainable economic development, including education, social services and infrastructure; 2) Environmental conservation, in a country with only $8 \%$ of the soil suitable for agriculture; 3) Culture, as a series of values needed for social progress; 4) Good governance underpinning all others (The Centre of Buthan Studies, 2012). 
The same Simon Kuznets (Nobel prized in 1971 for having shown the correlation between GNP per capita and the inequalities. He exposed the "Kuznets' Curve", through which he explained how inequality increases in the first phase of development, when the richest people invest their capital, until it touch a maximum value and then decrease with increasing of the GNP per Capita, corresponding to the redistribution of the richness created before (Kuznets, 1955), who in 1934 showed the Gross Domestic Product to the Congress of the United States with then President Franklin Delano Roosevelt - that was the beginning of continued work by the OECD (first OEEC) on the system of national accounts (Giovannini, 2010) -, introduced a number of concerns immediately after he "invented" this index, warning the same Congress about how «the welfare of a nation [can] scarcely be inferred from a measure of national income» (Kuznets, 1934), as far as such a measure was necessary after the economic crisis of ' 29.

The idea that mere wealth of a nation is insufficient to measure the well-being of citizens is now out from academic debates. By the time the world's institutions are working to find new policies capable of saying how you "live well", in order that this comfort level could be increased. A first step towards a common international political project, which is human-centred.

\section{The Human Development Index and the Equitable and Sustainable Welfare}

The Human Development Index - created by Pakistani economist Mahub ul Haq (1990; 1996), with the help of Amartya Sen - has fulfilled, and continues to fulfil, the extremely important task, of assisting purely economic indices as guidance in the implementation and in the monitoring of public policies. This index is a decimal number between 0 and 1 and is a synthetic measure that summarizes the standards built on the base of 3 fundamental variables: 1) The GDP at purchasing power parity; 2) The level of literacy; 3) Life expectancy.

$I_{i j}=\frac{\left(\max X_{i j}-X_{i j}\right)}{\left(\max X_{i j}-\min X_{i j}\right)}$

The first step consists in a measure of deprivation that a country $(j)$ suffer in each of the three variables above $(i)$, after the definition of maximum and minimum values given by actual values. Then it must be defined an average deprivation indicator:

$I_{j}=\frac{\sum_{i=1}^{3} I_{i j}}{3}$

The Human Development Index came out by subtracting $I_{j}$ from 1 :

$(H D I)_{j}=\left(1-I_{j}\right)$

Originally, the Human Development Index was the result of the arithmetic mean of the above three dimensions indices, which themselves were calculated using the relationship between the global maximum value of all sizes and the value of the State for which the index was calculated (UNDP, 1990). The strengths of this system are detected in the ease of reading the results, even by people who are not properly "experts" of statistical data. Policy makers were, therefore, facilitated in terms of data interpretation and, consequently, in fixing issues.

Despite the theoretical extent of this innovation, in practice there was no shortage of criticism, especially in relation to the quality of the data obtained: the statistical data used are not directly detected by UNDP, but uses data made available by UN agencies or directly by national agencies, which often devote more attention to purely economic surveys, omitting those important for the human development approach. And over, structurally speaking, the use of arithmetic mean as aggregate system does not appear to be the most appropriate method, because using this system means that the three index components: life expectancy, education and GDP, have the same weight in determining the final outcome. In this way the same average value amount of the index may indicate different levels of human development. A country with a population illiterate, a high GDP and a high life expectancy would have a similar HDI of a country with a low GDP, but with a totally educated population and longevity. The index also omits key font sizes, such as environmental sustainability, technological development, etc. (Sen, 2010).

To overcome, even if only partially, to those who have criticism to the HDI, in 2010, UNDP made some relevant changes in measuring well-being and development. First, the geometric mean is used as aggregate system of three "sub-indexes", which means that each value has a considerable weight in the calculation; but above all it inserted three others fundamental indices to capture more significant aspects for health and human development of the population: 
1. The Inequality-adjusted Human Development Index (I-HDI), which measures the level of human development of individuals in a given society, taking account of the degree of inequality in income distribution, health and education. The greater the difference between HDI and IHDI, the more pronounced will be the inequality in those fields (UNDP, 2010);

2. The Gender Inequality Index (GII), which emphasizes the differences in results between men and women in the three dimensions of health, education and the labour market. Women and girls, in fact, often face disadvantages in terms of access to education and to employment, as well as to health care, and that have a profound effect on their personal freedoms (UNDP, 2010);

3. The Multidimensional Poverty Index, which complete the measurement showing the multidimensionality of forms of deprivation and their overlap. It deals with the same dimensions covered by the HDI, by measuring the number of people below the poverty line and the deprivations they suffer. It can also be disaggregated by region or ethnicity and represents a powerful tool for implementing economic policies (UNDP, 2010). The MPI value is the product of two measures: the multidimensional headcount ratio and the intensity (or breadth) of poverty (UNDP, 2010).

In Italy, the debate on welfare and on the development of human capabilities, has found fertile ground in recent years, with the introduction of a new project starting in 2010 aiming at the construction of an aggregate index for measuring human development, called Equitable and Sustainable Well-Being (BES), which incorporates all theoretical project presented for the human development index, and then all the work of Nussbaum on well-being. The project curated by Istat and by the CNEL, with the collaboration of experts in the fields of statistics and sociology, has as objective the evaluation of the multidimensional welfare of Italian citizens, bearing in mind the fairness in the distribution of resources, and the sustainability of levels of well-being for future generations. The methodological framework used is the one provided by the OECD in 2006 (Hall et al. 2010), based on domains and on two macro-dimensions: human welfare and ecosystem's well-being, which in any case do not constitute a caesura, but are interesting in the intersections between the two spheres. According to these macro-dimensions, the Steering Committee of the Equitable and Sustainable Well-Being (Istat, CNEL and civil society) has identified two groups of domains: nine of them have direct impact on human and environmental well-being and the other three represents functional elements to improve social welfare. Each of them is devoted an entire chapter of the annual report of Istat on the Equitable and Sustainable Well-Being (Istat, 2016), published starting in 2013, and are listed as follows: 1) Health; 2) Education; 3) Work-life balance; 4) Economic well-being; 5) Social relationships; 6) Politics and institutions; 7) Safety; 8) Subjective well-being; 9) Landscape and cultural heritage; 10) Environment; 11) Research and innovation; 12) Quality of services.

For measuring those dimensional domains were detected 130 markers (201 from 2017) to the availability of data collected on a regular basis and made available from official national sources. There is also the possibility to disaggregate these indicators for structural variables (sex, level of education, age, etc.), as well as on a territorial basis. Law n. 163/2016, which edited content of the state budget, establishes the link between equitable and sustainable welfare indicators and economic and budgetary planning, as well as it creates the Committee for fair and sustainable welfare indicators at Istat, chaired by the Minister for Economic Affairs, and composed by the Chairman of Istat, by the Governor of the Bank of Italy and by two experts. The crucial importance of a new economic vision for the same programming policy is now nationally certified and, above all, acquires a normative value (Italian Council of Minister, 2017). The table below show the correlation between the BES indicators and the Sustainable Development Goals - 2030.

Tab. 1 - BES indicators and Sustainable Development Goals

\begin{tabular}{|l|l|}
\hline BES & SDGs \\
\hline 1. Health & $\begin{array}{l}1 \text { indicator in GOAL 2 "Zero hunger"; } \\
3 \text { indicators in GOAL 3 "Good Health and Well Being". }\end{array}$ \\
\hline 2. Education & $\begin{array}{l}5 \text { indicators in GOAL 4 "Quality Education"; } \\
1 \text { indicator in GOAL 8 "Decent Work and Economic Growth". }\end{array}$ \\
\hline 3. Work-life Balance & $\begin{array}{l}1 \text { indicator in GOAL 5 "Gender Equality"; } \\
2 \text { indicators in GOAL 8 "Decent Work and Economic Growth". }\end{array}$ \\
\hline 4. Economic Well-being & $\begin{array}{l}3 \text { indicators in GOAL 1 "No Poverty"; } \\
2 \text { indicators in GOAL 10 "Reduced Inequalities"; } \\
1 \text { indicator in GOAL 11 "Sustainable Cities and Communities". }\end{array}$ \\
\hline
\end{tabular}




\begin{tabular}{|l|l|}
\hline 5. Social Relationships & \\
\hline $\begin{array}{l}\text { 6. Politics and } \\
\text { Institutions }\end{array}$ & $\begin{array}{l}4 \text { indicators in GOAL 5 "Gender Equality"; } \\
3 \text { indicators in GOAL 16 "Peace, Justice and Strong Institutions", }\end{array}$ \\
\hline 7. Safety & 2 indicators in GOAL 16"Peace, Justice and Strong Institutions". \\
\hline 8. Subjective Well-being & \\
\hline $\begin{array}{l}\text { 9. Landscape and } \\
\text { Cultural Heritage }\end{array}$ & 1 indicator in GOAL 11 "Sustainable Cities and Communities". \\
\hline $10 . \quad$ Environment & $\begin{array}{l}1 \text { indicator in GOAL 1 "No Poverty"; } \\
1 \text { indicator in GOAL 6 "Clean Water and Sanification"; } \\
1 \text { indicator in GOAL 7 "Affordable and Clean Energy"; } \\
1 \text { indicator in GOAL 8 "Decent Work and Economic Growth"; } \\
1 \text { indicator in GOAL 11 "Sustainable Cities and Communities"; } \\
1 \text { indicator in GOAL 12 "Responsible Consumption and Production"; } \\
1 \text { indicator in GOAL 15 "Life on Land". }\end{array}$ \\
\hline $\begin{array}{l}\text { 11. Research and } \\
\text { Innovation }\end{array}$ & 3 indicators in GOAL 9 "Industry, Innovation and Infrastructure". \\
\hline 12. Quality of services & 1 indicator in GOAL 16 "Peace, Justice and Strong Institutions". \\
\hline
\end{tabular}

Source: ISTAT, Report on BES 2017

\section{Results}

With the introduction of the concept of capability, it is proposed a re-evaluation of the meaning of human rights with reference to the relationship with politics. It is believed that mention capability is more fruitful than talking about rights, since for the first institutional intervention is required for their promotion and their development, while it is somehow inherent in the definition of the rights that leads us to believe that they are insured without positive political action of defence and promotion. In addition, you may move a consideration concerning the relationship between scientific progress and acquiring "new" rights, an issue that leads back to most of bioethics and ethical issues of our time. Well, modern liberalism has led to scientific progress without limits, or rather, with the only limit of feasibility. New technological discoveries, for example in the biomedical field, created a movement for the protection of the rights that born from them, thus generating new issues around the legitimacy of protection and promotion of those rights.

From this you may already understand the innovative extent of the theory. Having proposed a distance from the legal and political tradition based on the protection of fundamental rights is a step toward a new way of thinking about society and politics, which projects towards innovative scenarios in considering welfare and human development. The new models for the measurements of human well-being are only the first steps to an innovative view of what we must do for human development. The drawing-up of these new indices is involving scientific research all over the world, and it is providing to governments fundamental tools for development-focused economic and social policies, according to the international pollical line, given by UN with the Sustainable Development Goals or with the United Nations Development Programme.

\section{References}

Alessandrini, G. (2013). Capacitazioni a formazione: quali prospettive? Formazione\&Insegnamento, 11 (1), pp. 53-67.

Clark, D. A. (2008). The Capability Approach: Its Development, Critiques and Recent Advances, in R. Ghosh, K. R. Gupta, ed., Development Studies, Volume II, 1st ed. New Delhi: Atlantic Books and Distributors.

Council of Ministers (2017). Il Benessere equo e sostenibile nel processo decisionale. The Economic and Finance Document, Italian Council of Ministers Documents.

Giovannini, E. (2010). Dal Pil al benessere: nuovi indicatori per misurare il progresso della società. ISTAT annual Report, pp. 61-85.

Hall, J., Giovannini, E., Morrone, A., Ranuzzi, G. (2010). A Framework to Measure the Progress of Societies. OECD Statistics Working Papers, 5. URL = <http://www.oecd-ilibrary.org/economics/a-framework-tomea sure-the-progress-of-societies_5km4k7mnrkzw-en>. 
ISTAT (2017), BES. Il benessere equo e sostenibile in Italia, Rome: National Statistical Institute. URL = <https://www.istat.it/it/files/2017/12/Bes_2017.pdf>.

Kennedy, R. F. (1968). Discourse to the Students. University of Kansas, $18^{\text {th }}$ March 1968. URL = <http://www.theguardian.com/news/datablog/2012/may/24/robert-kennedy-gdp>.

Kuznets, S. (1955). Economic Growth and Income Inequality. The American Economic Review, 45 (1), pp. 1-28.

Kuznets, S. (1934). National Income, 1929-32. U.S. Congress, Senate, S. Doc. 124, 73rd Cong., 2d sess.

Nussbaum, M. (2000). Woman and Human Development. The Capability Approach. Cambridge (MA): Cambridge University Press.

Nussbaum, M. (2001). Upheavals of Thought. Cambridge: Cambridge University Press.

Nussbaum, M. (2004). Hiding from Humanity: Disgust, Shame and the Law. Princeton: Princeton University Press.

Nussbaum, M. (2006). Frontiers of Justice: Disability, Nationality, Species Membership. Cambridge (MA): Harvard University Press.

Nussbaum, M. (2010) From Disgust to Humanity: Sexual Orientation \& Constitutional Law. Oxford: Oxford University Press.

Nussbaum, M. (2011). Creating Capabilities. The Human Development Approach, Cambridge (MA): Harvard University Press.

Pizzo, A. (2014). Chi è libero, eguale ed indipendente? MathaNussbaum su disabilità e giustizia, in «Diritto \& Diritti - Rivista giuridica elettronica», ISSN 1127-8579. URL $=<$ http://www.diritto.it/docs/36133-chi-illibero-eguale-ed-in dipendente-marthanussbaum-su-disabilit-e-giustizia $>$.

Protasi, S. (2012). Interview: Martha Nussbaum. Humana.Mente, 22, pp. 233-242.

Rawls, J. (1993). Political Liberalism. New York: Columbia University Press.

Robeyns, I. (2011). The Capability Approach. The Stanford Encyclopedia of Philosophy (Winter 2016 Edition). Edward N. Zalta (ed.). URL = <https://plato.stanford.edu/archives/win2016/entries/capability-approach/>.

Sen, A. (1985). Justice: Means versus Freedoms. Philosophy and Public Affairs, 19 (2), p. 111-121.

Sen, A. (2010). Introduction. The Real Wealth of Nations: Pathways to Human Develpment, da Human Develpment Report, in UNDP, New York: Oxford Oxford University Press URL = <http://hdr.undp.org/sites/default/file s/reports/270/hdr_2010_en_complete_reprint.pdf>.

Sen, A., Nussbaum, M. (1993). Quality of Life. Oxford: Clarendon Press.

Stiglitz, J. E., Sen, A., Fitoussi, J. P. (2009). Report of the Commission of Experts of the President of the United Nations General Assembly on Reforms of the International Monetary and Financial System, Report by the Commission on the Measurement of Economic Performance and Social Progress.

European Commission Documents, URL = <http://ec.europ a.eu/eurostat/docum ents/118025/11812 3/Fitoussi+Commis sion+report>.

Thomas, L. (1980). Sexism and Racism: Some Conceptual Differences. Ethics, 90 (2), pp. 239-250.

UNDP (1990). Concept and Measurement of Human Development. Human Develpment Report. New York: Oxford Oxford University Press, 1990. URL = <http://hdr.undp.org /sites/default/files/r eports/219/h dr_19 90_en_complete_nostats.pdf>.

UNDP (2000). Human Rights and Human Development. Human Development Report. New York: Oxford University Press.

Williams, B. (1987). The Standard of Living: Interests and Capabilities, in G. Hawthorne, ed., The Standard of Living, 1st ed. Cambridge: Cambridge University Press, 1987. 